\title{
Management of Lagophthalmos in Leprosy
}

\author{
W. M. LENNOX, B.sG., F.R.G.s.(ENG.), F.R.G.s. (EDIN.) \\ C/o. The British Leprosy Relief Association, \\ 8 Portman Street, London $W$. I
}

Lagophthalmos, or paralysis of the orbicularis orbis muscle, may result from injuries to the facial nerve, non recovery of Bell's Palsy, and leprosy. Syphilis and Poliomyelitis are rare causes. Exposure conjunctivitis, keratitis ectropion and dacrocystitis are common complications. About one quarter of leprosy cases have corneal anaesthesia, and about one in ten show ectropion or lacrymal sac infection. In endemic areas the overwhelming majority of cases, and much consequent eye morbidity, are due to leprosy.

The combination of lagophthalmos with corneal anaesthesia is particularly dangerous, and requires urgent treatment. This is seen most often in long-standing lepromatous patients It is much less common in the tuberculoid and dimorphous forms. In these, lagophthalmos is a special hazard of reaction, particularly in paticnts with large facial macules.

Leprosy neuritis interrupts conduction in the facial nerve either just distal to the stylomastoid foramen (giving an extensive facial paralysis), or the zygomatic branches are affected where they lie superficially in the cheek. Occasionally enlarged branches may be palpated against the zygoma. The Proprioceptive fibres of the facial muscles travel in the fifth cranial nerve and make multiple connections with motor twigs within the facial muscles. There thus exist anatomical connections between sensory and motor nerves in the face, which may permit M.leprae from the sensory nerves to spread into the facial nerve. This may explain the association between large facial macules and lagophthalmos.

\section{Signs and Symptoms}

Reduction in the frequency of blinking may be noted. Excessive watering from profuse reflex tear secretion and subclinical ectropion, and burning pain, are prominent symptoms. Very early lag can be detected by gently attempting to open the eye manually against the patient's effort to keep it closed. Degrees of lag in excess of $0.5 \mathrm{~mm}$. are easily seen, and in the fully developed condition even the upward roll of the eye may fail to bring the cornea fully under cover of the upper lid. Lag exceeding $12 \mathrm{~mm}$. is not uncommon. In these conditions exposure changes are likely to be found over the lower one third of the cornea, which becomes dry and vulnerable.

\section{General Management}

Many eyes are encountered with minor lagophthalmos, adequate corneal coverage, and freedom from complications. Since most mild cases progress to total paralysis, they should be seen regularly, and be provided with a suitable oil and a mildly antiseptic lotion (see below). Protective spectacles may be required for occupational hazards. Anaesthesia of the hands requires specific use of the eyes for avoidance of injury, and any risk to vision is therefore doubly dangerous.

Many patients suffer from vitamin deficiencies and it is reasonable to give supplements of vitamins $\mathrm{A}$ and $\mathrm{C}$. Exposure changes are treated energetically along the usual lines. Ulceration of the cornea is an emergency and must be treated by the method indicated for the particular case. Once complications are controlled, the management becomes that of the uncomplicated case. A mild antiseptic lotion (e.g. $\frac{1}{2}$ oz. zinc in $5 \%$ boracic acid lotion, tds.) should be instilled during the day and sterile castor oil drops at night, to prevent drying during sleep. Attention may now be directed to the paralysis.

\section{Management of Paralysis}

Lagophthalmos may be 'acute', subtotal, or complete.

'Acute' Lagophthalmos: This is lagophthalmos of sudden onset, usually associated with reaction. A smali proportion of these cases recover when 
the reaction subsides: the majority, unfortunately, do not. If the case is seen early, the prospects for recovery can be enhanced by exhibiting steroids. A course commencing with a large dose (e.g. Prednisolone $60 \mathrm{mgm}$. daily orally) and tapering down to nil within I4-2 I days, is useful in practice, and avoids some of the dangers inherent in steroid therapy. These are not inconsiderable, and it is suggested that any who are unfamiliar with these drugs should secure the advice of a physician before prescribing them.

While awaiting the outcome, the general measures noted above are instituted. A severe lag may require support of the lower eyelid by strapping, and very occasionally a temporary tarsorrhaphy is required. After ten days, galvanic stimulation may be started in an effort to minimise atrophy of denervated muscle fibres.

There is no general agreement about how long one should wait before abandoning hope of recovery. A practical rule is to treat partial recoveries as described below, and to advise surgery where no recovery commences within three months.

Subtotal Paralysis: This frequently results from incomplete recovery of an 'acute' lagophthalmos. Residual motor activity is present in the orbicularis, and the lag is insufficient to uncover the cornea. These cases justify a trial of physiotherapy aimed at hypertrophying fibres with intact innervation. The patient practises eye closure many times a day, and courses of faradic stimulation are given. Progress is assessed by periodically measuring the gap between the eyelids. Oil and antiseptic drops are prescribed.

A regular and careful watch must be kept for exposure changes in these cases as well as in those with 'acute' lag. Sommerset and Sen (1957) warn about assuming that partial recoveries afford adequate protection for the eye. They advise that 'all cases showing any degree of weakness of the lid movements should, therefore, be carefully watched for involvement of the cornea, and a tarsorrhaphy (lateral or medial) operation performed as a preventative measure in most cases'. In these rircumstances, however, it would be functionally and cosmetically more appropriate to perform a temporalis transfer.

Total Paralysis: Total paralysis requires surgery. The presence of corneal anaesthesia is an absolute indication for early operation. The methods at present available are:

I. Tarsorrhaphy

2. Static eyelid slings

3. Sommerset's operation

4. Temporalis transfer

Tarsorrhaphy is a simple procedure, and is reversible. Its main uses are: reaction cases with wide lag where there is hope of recovery, and the highly positive or elderly patient. It does not preclude a later temporalis transfer. The static eyelid sling may be considered for the old or unintelligent patient with lower corneal changes. The orbital fissure is permanently narrowed, though over the long term there may be some recurrence of sagging of the lower lid. Sommerset's operation consists of running a silk or nylon suture round the lid margins. The disadvantage is the risk of infection, and some residual orbicularis action is necessary to effect closure.

The operation of temporalis musculofascial sling, devised by Gillies, has proved to be of immense benefit in lagophthalmos. It is the procedure of choice in the majority of cases, and will be described more fully. The technique is not difficult to master (See Antia, I 963: Andersen i 96 I) and deserves to be more widely known.

A modification which avoids reversing muscle polarity has been described by fohnson (I 962).

Pre-operatively, the conjunctival sac and the lacrymal sac should be free from infection, and patency of the nasolacrymal duct is confirmed by syringing. The scalp is completely shaved and the field is prepared with $\mathrm{I} \%$ cetrimide solution.

The operation is carried out under local infiltration anaesthesia $\left(\frac{1}{2} \%\right.$ xylocaine with I : 200,000 adrenaline), or light general anaesthesia. The head is draped leaving the side of the head and the upper face exposed.

Figures I to 4 illustrate stages of the operation. Incision $\mathrm{A}$, within the hair line, extends from the upper border of the zygoma to $2 \mathrm{~cm}$. above the superior temporal line. It is deepened to the temporal fascia, which is exposed by retraction of the wound margins. A strip of fascia is outlined by a pair of vertical incisions half an inch apart, starting below at the zygoma and ending in periosteum half an inch above the superior temporal line. The strip is elevated from the subjacent temporalis muscle but is left attached 


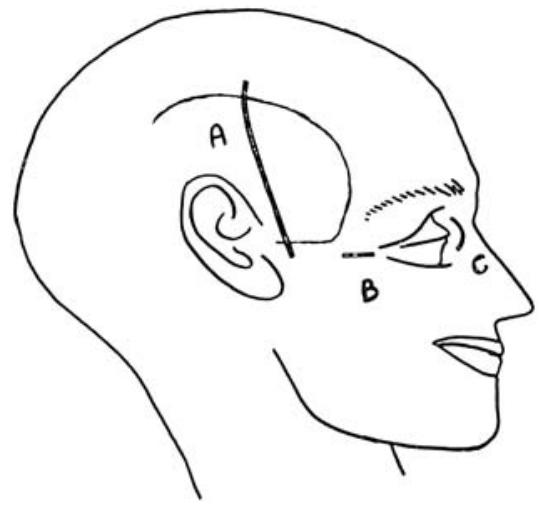

FIG. I

Incisions

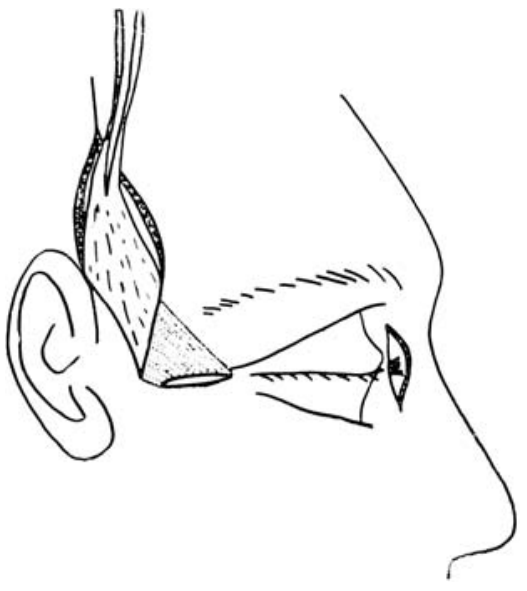

FIG. 3

Single fascial strip divided into two thin slips

above. (Fig. 2). At the lower end the fascia divides into superficial and deep layers inserting into the inner and outer margins of the superior surface of the zygomatic arch. The space between the layers contains vessels; this configuration may occasion a little difficulty in freeing the strip at the lower end, if forgotten. The upper end of the strip is freed by a transverse incision through the periosteum, followed by downward stripping with a periosteal elevator. This process also elevates temporalis muscle from the bone of the superior temporal fossa, and by splitting the fibres on each side a muscle slip is fashioned in

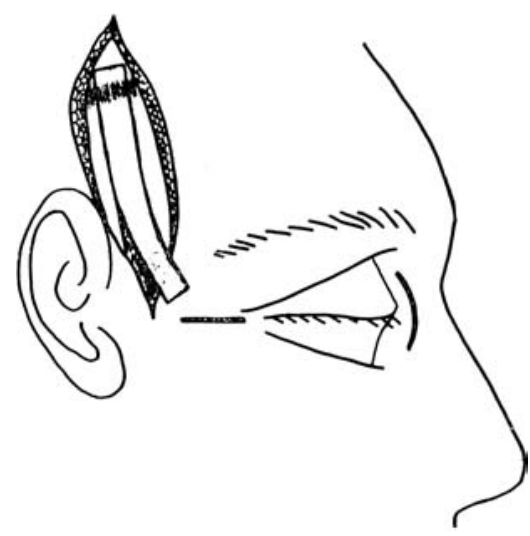

FIG. 2

Fascial strip outlined and elevation commencing

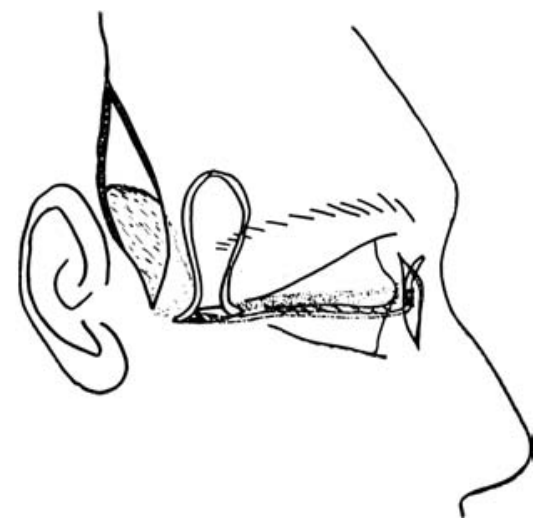

FIG. 4

Eyelids tunnelled, lower eyelid slip in situ, upper eyelid slip ready for passing

continuity with the fascial strip. The muscle is freed sufficiently to allow the fascia to reach to the inner canthus on swinging the slip forwards. Its nerve and vascular supply, entering deeply and below, is not disturbed.

From incision A a subcutaneous tunnel is fashioned to a $\mathrm{I} \mathrm{cm}$. incision at the outer canthus (incision B). The slip is placed in this bed, so that the musculo-fascial junction lies at the outer canthus. The junction can be reinforced with a single suture if desired. The fascia is delivered through the wound, having been divided longitudinally into two strips (Figs. 3 and 4). A 
I $\mathrm{cm}$. vertical curved incision is made, $5 \mathrm{~mm}$. medial to the inner canthus (incision $\mathrm{C}$ ), and by careful blunt dissection the medial canthal ligament is defined. Damage to the more deeply placed lacrymal sac must be avoided. The inner and outer incisions are joined by narrow subcutaneous tunnels fashioned by delicate blunt subcutaneous dissection close to the margins of both lids. This is facilitated by previous infiltration with anaesthetic solution: occasionally small horizontal counterincisions at the mid points of the lid margins are helpful. The fascial strips are passed through the tunnels, and then deep to the medial canthal ligament (Fig. 4). With high tension applied to the lower eyelid slip and the slack taken up from the upper slip, the upper eyelid will overlap the lower, and in this position the slips are sutured to each other and to the medial canthal ligament.

After checking haemostasis, the incisions are closed without drainage: a pressure dressing is applied to the temporal wound. A little antibiotic ointment is injected between the eyelids.

\section{Post Operative Management}

For Io days the patient takes fluids only by mouth, and soft diet for a further io days. Normal diet is then allowed, and chewing is encouraged. The patient is given a piece of sponge rubber to chew upon. The sutures around the eye are removed at four days, the temporal sutures after a week. Eyelid oedema absorbs in 3 or 4 days. After commencement of chewing exercises full voluntary closure is obtained in 2 to 4 weeks. The patient must be taught to clench his teeth periodically while out in the open to mimic the blink reflex. Later the eye will remain closed during sleep.

\section{Lagophthalmos and Ectropion}

The presence of ectropion imparts special difficulties to lagophthalmos repair. Great care must be taken to place slings exactly along the lid margin; failure to do this may aggravate the eversion. It is recommended that a standard ectropion repair be performed first, and that the paralysis be dealt with at a second operation. Otherwise, tarsorrhaphy is a safer procedure. For lag with mild ectropion, lateral tarsorrhaphy at the time of temporalis transfer is advised. The tarsorrhaphy may be released later when the transfer has developed its full power.

\section{Causes of Suboptimum Results}

The incidence and causes of suboptimum results are illustrated by analysis of the results of 43 eyes (30 patients) operated under the South Indian Peripheral Surgical Assistance Scheme. The operations to be reported were performed by six different surgeons in seven different hospitals, employing the technique described above.

\section{Material and Methods}

One patient could not be traced. Five with a follow up of less than three months are also excluded, although all were graded good or excellent. Thus 37 operations on 24 patients are available for report. Ages varied from 23 to 50 years; length of follow up varied from three months to two years. Pre-operatively, the widths of the orbital fissures (on attempting closure) varied between five and $15 \mathrm{~mm}$. the majority being about I $\mathrm{cm}$. No patient in this series had corneal anaesthesia, but in $50 \%$ exposure changes, usually mild, were present.

Since there is no accepted standard for grading the results of this operation, a method based upon attainment of effective corneal coverage (the main objective of surgery) was devised. The criteria are:

$\begin{array}{ll}\text { Excellent } & \text { complete closure on moderate } \\ \text { Goffort } & \text { - } \\ \text { Good } & \text { effort, but no lag present on moderate } \\ & \text { forced effort } \\ \text { Fair } & \text { lag persists, but the cornea is } \\ & \text { covered on effort } \\ \text { Poor } \quad \text { lag persists, and the cornea is not } & \text { adequately covered on effort. }\end{array}$

'Moderate effort' is the degree of effort adopted by a patient when asked to close his eyes. It is usually submaximal.

\section{Results}

Thirty eyes were graded good or excellent, and seven fair or poor (8I \% \& $19 \%$ respectively).

Particular interest attaches to the $19 \%$ of unsatisfactory results, which are detailed in the following table.

\section{I54 Leprosy Review}




\begin{tabular}{|c|c|c|c|c|c|}
\hline & Patient & $\begin{array}{l}\text { No. of } \\
\text { eyes }\end{array}$ & $\begin{array}{l}\text { Post Operative } \\
\text { Complications }\end{array}$ & Remarks & $\begin{array}{l}\text { Follow } \\
\quad U p\end{array}$ \\
\hline Poor \{ & V.R. & 2 & $\begin{array}{l}\text { Canthal Sepsis } \\
2 \text { eyes }\end{array}$ & $\begin{array}{l}\text { A beggar: did not co- } \\
\text { operate post-operatively. } \\
\text { On effort could achieve } \\
\text { corneal coverage, but } \\
\text { made no effort to use his } \\
\text { transfer except when } \\
\text { supervised. }\end{array}$ & $6 / 12$ \\
\hline \multirow{4}{*}{ Fair } & A & I & Canthal Sepsis & $\begin{array}{l}\text { Patient co-operated well, } \\
\text { but slings lost tension. }\end{array}$ & $6 / 12$ \\
\hline & V. & I & nil & $\begin{array}{l}\text { Previous tarsorrhaphy } \\
\text { released at time of trans- } \\
\text { fer: tension probably } \\
\text { insufficient ab initio. }\end{array}$ & $6 / 12$ \\
\hline & A.N. & I & Canthal Sepsis & Loss of tension & $3 / 12$ \\
\hline & B. & 2 & Canthal Sepsis & $\begin{array}{l}\text { Loss of tension in both } \\
\text { eyes. Both improved to } \\
\text { 'Fair' by exploring and } \\
\text { re-attaching the slips } \\
\text { which were found to have } \\
\text { pulled back into the eyelid. }\end{array}$ & I year \\
\hline
\end{tabular}

Infection at incision ' $\mathrm{C}$ ' was the commonest complication. It occurred in six of the seven eyes graded fair and poor, but it also occurred in five other eyes which were graded 'good'. It is therefore not necessarily prejudicial to a satisfactory result (fig. 5), but in three of the patients listed in the table it was the most likely cause of loss of tension and consequent downgrading. In case $\mathrm{B}$, subsequent exploration revealed that the slips had failed to attach to the medial canthal ligament, and had, in fact, pulled back into the eyelids.

\section{Discussion}

It will be noted that a 'good' result is permitted 2 or $3 \mathrm{~mm}$. of lag on moderate effort, providing that the cornea is covered. In a number of cases the lag was apparent and persisted from the early weeks, and it must be assumed that the initial tensioning was too low. This may have contributed to the result in patient V. ('Fair'). This emphasises the need for high tensioning at operation: over tensioning is really not possible.

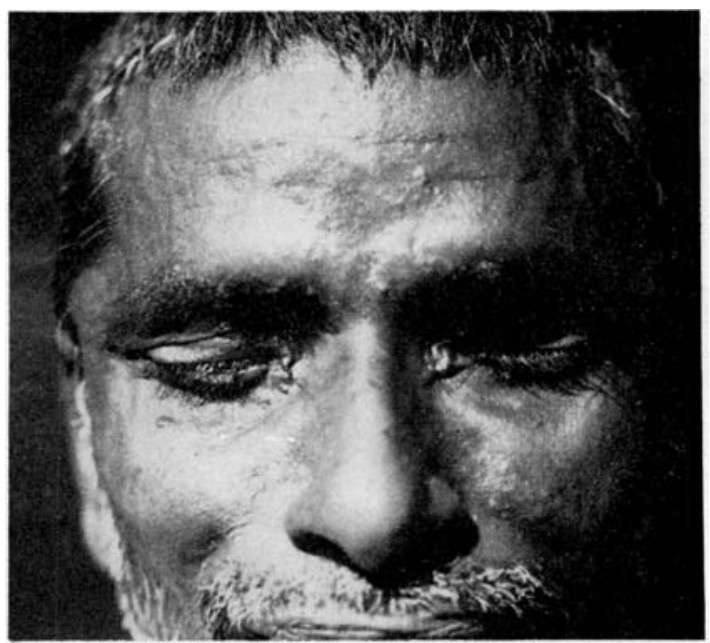

FIG. 5

Canthal sepsis with residual stitch granulomas. Nevertheless Left eye graded Excellent. Right eye down graded to Good because of $2 \mathrm{~mm}$. lag and trace of eversion of the lower lid. Slings must be placed accurately along the margins of the lids 
Since canthal sepsis was the commonest complication the placing of incision $\mathrm{C}$ well medial to the canthus must be stressed. A small flap of skin and subcutaneous tissue is formed which falls back into place when retraction is released. The canthal skin is very thin; it must be handled with the utmost gentleness, and be sutured meticulously.

The causes of failure in this series may be summarised as follows :

( I) Loss of tension, occasionally following canthal sepsis, but not specifically associated with this complication.

(2) Inadequate tensioning at the time of operation. Failure to obtain sufficient tension at operation resulted in a number of cases being downgraded from 'excellent' to 'good'.

(3) Failure to co-operate in aftercare and physiotherapy. Early chewing might conceivably pull the slips free from the medial canthal ligament.

(4) Error of Selection. Case V.R., a beggar, would have fared better with a tarsorrhaphy (Fig. 6).

Andersen (I 96 I) reports $80 \%$ success in a series of ro eyes with one to three months follow up. Several cases in the present series were graded

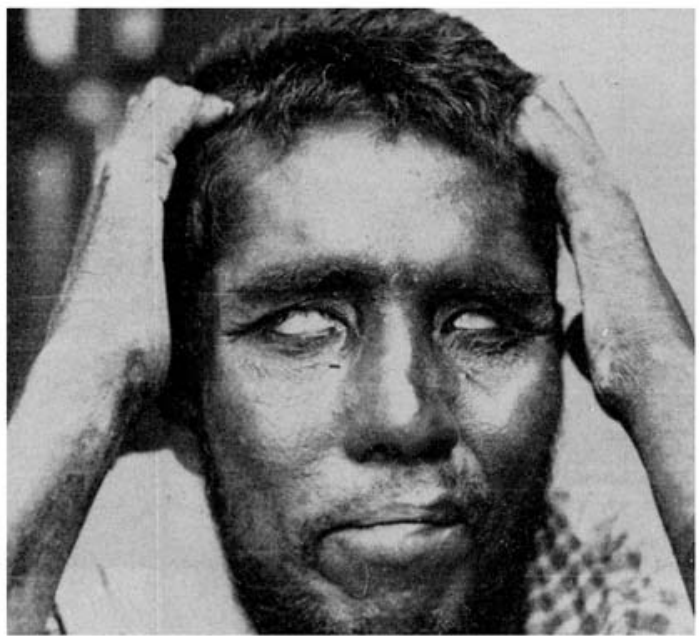

FIG. 6

Case V.R. Maximal effort just covers the corneae, but patient did not achieve this degree of closure unless supervised. Graded Poor 'excellent' initially, to be downgraded to 'good' subsequently with the recurrence of a small amount of lag (Fig. 7). Possibly these cases were not tensioned adequately, and it is not unreasonable to wonder if they may require further downgrading at a future date. Because of the possibility of late deterioration, it is reasonable to advise patients to perform specific exercises regularly each day, after discharge.

\section{Summary and Conclusion}

A successful temporalis transfer gives support to the paralysed lower lid, and repositions the puncta for draining tears. It provides voluntary power for closing the orbital fissure, and promotes reversal of exposure changes in the eye. It substitutes for the blink reflex, since the eyelids move with every contraction of the temporalis muscle: and resume their wiping and lubricating actions. Effective protection is afforded to the cornea rendered insensitive by leprosy. The cosmetic effect is pleasing; the risks of blindness are minimised.

A series of 37 operations is presented. Infection of the medial canthal wound is the commonest complication. Nevertheless, the operation carries a satisfactory success rate in the hands of non-specialised surgeons, providing the

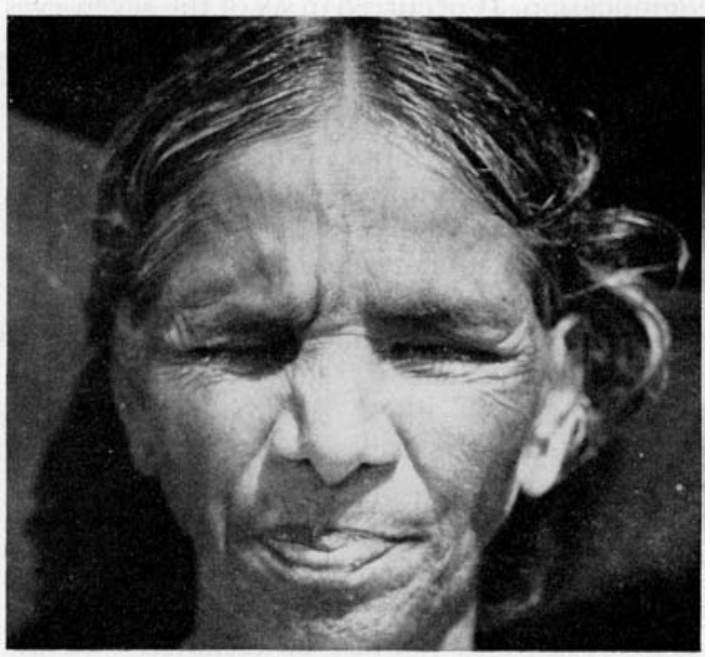

FIG. 7

Maximal effort gives full closure. Moderate effort leaves $2 \mathrm{~mm}$. of lag. Graded Good. (Left eye)

\section{56 Leprosy Review}


technique and post-operative regime are carefully followed.

It is the author's hope that the operation will be used more frequently.

\section{AGKNOWLEDGEMENTS}

It is a pleasure to acknowledge the interest and enthusiasm of all those surgeons who participated in the peripheral surgical project in South India, and who permitted me to examine and comment upon their cases. Much of the follow up data was collected and recorded by
John Vinookumar Esq., to whom my special thanks are due.

\section{REFERENCES}

Antia, N. A. Reconstruction of the Face in Leprosy. Annals of Royal College of Surgeons. 32, ( I 963), 7 I .

Andersen, J. G. Surgical Treatment of Lagophthalmos in Leprosy, by the Gillies Temporalis Transfer. British Journal of Plastic Surgery, 14, ( I 96 I), 339. Johnson, H. A. A Modification of the Gillies Temporalis Transfer for the surgical treatment of the lagophthalmos of Leprosy. Plastic and Reconstructive Surgery. 30, (1962), 378. SOMMERSET, E. J. and SEN, N. R. Leprosy in India. 29, ( I957), I 42 . 